\title{
Weight, height and eruption times of permanent teeth of children aged 4-15 years in Kampala, Uganda
}

Annet Kutesa ${ }^{1}$, Eriab Moses Nkamba ${ }^{1}$, Louis Muwazi ${ }^{1}$, William Buwembo ${ }^{2}$ and Charles Mugisha Rwenyonyi ${ }^{* *}$

\begin{abstract}
Background: Tooth eruption is a continuous biological process by which developing teeth emerge through the jaws and the overlying mucosa to enter into the oral cavity. Tooth eruption time and sequence are important factors in dental treatment planning, particularly in orthodontics, but also in forensic dentistry to estimate age of a child. Tooth eruption time is influenced by many factors. In this study we set out to determine the timing of eruption of permanent teeth and assess its association with the height and weight of school children aged 4-15 years in Kampala, Uganda.

Methods: This was a cross sectional study comprising of 1041 healthy Ugandan children: boys/girls (520/521) who were consecutively selected from two primary schools in Kampala. The children were clinically assessed for tooth emergency through the oral mucosa as well as measuring their weight and height. The mean and standard deviation of tooth eruption time was estimated for boys and girls. Bivariate analysis was used to assess any significant association between tooth eruption time and demographic variables. Pearson and partial correlation analyses were used to assess any significant association between the tooth eruption time and anthropometric measurements of the children.
\end{abstract}

Results: Generally, the mean eruption times for girls were lower compared to boys except for three teeth (\#25, \#32 and \#42) which erupted earlier in boys. The average difference in mean eruption times of all teeth between boys and girls was found to be 0.8 (range, $0-1.5$ ) years. In partial correlation analysis, mean tooth eruption times were positively, but not significantly associated with height while controlling for weight except for the mandibular left central incisor (\#31). On the other hand, in partial correlation analysis, mean tooth eruption times were positively associated with weight while controlling for height except for tooth \#11,\#16, \#26 and \#41. The weight of the child was significantly correlated with mean eruption times in $50 \%$ of the teeth.

Conclusion: In the present study, the mean tooth eruption times for girls were lower compared to boys except for three teeth (\#25, \#32 and \#42). The height of the child did not show any significant influence on the tooth eruption times while the influence of weight on tooth eruption times was non-conclusive.

Keywords: Height, Permanent teeth, Tooth eruption age, Uganda, Weight

\footnotetext{
* Correspondence: mrwenyonyi@chs.mak.ac.ug

${ }^{1}$ Department of Dentistry College of Health sciences, Makerere University,

P.O. Box 7072, Kampala, Uganda

Full list of author information is available at the end of the article
} 


\section{Background}

Tooth eruption time and sequence are important factors in dental treatment planning especially in orthodontics, but also in forensic dentistry to estimate age of a child. Tooth eruption is a continuous biological process by which developing teeth emerge through the jaws and the overlying mucosa to enter into the oral cavity and contact the teeth of the opposing arch [1]. Several studies $[2,3]$ have shown that eruption of the permanent teeth is orderly, sequential and age-specific event. Generally, permanent teeth have been found to erupt between the ages of 5 to 13 years, except the third molars which do so between 17 and 21 years [2,3]. Furthermore, tooth eruption time as well as the sequence of tooth eruption have been reported to vary with races [2,4-6].

It has also been reported that some other variables like genetics, hormonal factors, geographical location, ethnicity, sex, economic status, nutrition and growth exert their influences on tooth eruption time [7,8]. A few studies have indicated a relationship between the eruption times with the weight and height of the children. Children who are below average weight and height have been shown to have a later eruption times than those who are within the standard range [4,9]. Khan [10] reported that tall children exhibited delayed tooth eruption irrespective of their weight while heavy and short children had early eruption. Agarwal [2] found that for the same age group, boys with more sexual maturity had enhanced dental eruption, in support of the earlier findings [11,12].

Most of the literature on dental development is essentially from outside Africa, which may not be applicable to the African population due to racial and environmental differences. The only study [13] on tooth eruption among Ugandan children was done more than 40 years ago, over which environmental and socioeconomic changes have taken place. The purpose of this study was to determine the timing of eruption of permanent teeth and assess its association with height and weight of children aged 4 to15 years in Kampala, Uganda.

\section{Methods}

\section{Study setting}

This was a cross sectional study in randomly selected schools within Kampala. Kampala is the metropolitan city of Uganda and comprises of five administrative municipalities namely; Kawempe, Central, Lubaga, Makindye and Nakawa. The study took place in two randomly selected municipalities: Lubaga and Makindye. The two municipalities have an estimated day population of about 900,000 people. The population is multi-ethnic with people from all districts of Uganda. A list of schools with kindergarten and primary sections within the two selected municipalities was obtained from Kampala City Council Authority Education office. One school was randomly selected from each of the municipalities: Wabigalo Day and Boarding School in Makindye Municipality and Happy Years Primary School, Kabuusu in Lubaga Municipality.

\section{Subject selection}

The children were recruited consecutively from the two schools. The selection criteria were that a child had to be a healthy Ugandan of African decent, aged 4 to 15 years and consented to participate in the study. The age and nationality of the child were ascertained from school records where 3 children were excluded for being nonUgandans. In order to be considered healthy, a child had no history of systemic or chronic disease(s), thus 4 children were excluded: 1 for having epilepsy; 1, oral cleft and 2 sickle cell disease leaving a total of 1041 children for the study.

\section{Ethical considerations}

Ethical approval was obtained from Makerere University School of Medicine Institutional Review Board. Permission to carry out the study was obtained from Kampala City Council Authority Education office and the respective heads of schools. Written consent was obtained from the parents/guardians on behalf of the children and assent was also obtained from the study children in accordance with Helsinki Declaration [14].

\section{Calibration of examiners}

Prior to the field survey, four dentists (research assistants) were trained by a human anatomist (WB) in data collection on children $(n=25)$ of St. Martin Primary School, Kampala. They were trained in clinical assessment of an erupted and not erupted tooth. They also trained in the measurement of height and weight of the children. The mean inter-examiner consistence in recording tooth emergence was 100\%; weight, 96\% (range, 94\%-98\%) and height, 95\% (range, 93\%-98\%).

\section{Data collection}

The data were collected from the study children by 4 research assistants who had previously been calibrated in the data collection. The demographic information included sex and date of birth. The date of birth was verified from the school records and was used to compute the age of the child. Dental examination of the children was conducted in broad day light with the help of a plane mouth mirror and pair of tweezers. The child was lying supine on a school wooden bench with the head resting on the examiner's lap who was seated at 12 o'clock position and inclined forward to fully access the child's oral cavity. The teeth were cleaned of food debris with cotton wool for proper visibility. Each permanent tooth was recorded using the two digit system of the Fedération Dentaire Internationale notation [15]. The 
emergence stages of the teeth into the oral cavity are classified into four stages [5]. The stages are defined as $0=$ the tooth not visible in the oral cavity; $1=$ at least one cusp visible in the oral cavity; 2 = the entire occlusal surface/mesio-distal width of the tooth visible; and $3=$ the tooth in occlusion or at the occlusal level if the antagonistic tooth was not fully erupted or missing. For purposes of the present study, we recorded a tooth as having erupted when any part of the crown was visible through the oral mucosa (i.e. stages 1, 2 and 3) defined as category 1 and when not erupted $=0$. Recording of extracted teeth due to caries was based on World Health Organisation guidelines [16]. Wisdom teeth were excluded. The study was school based and could not assess any congenitally missing teeth due to lack of appropriate radiological facilities like $\mathrm{x}$-rays.

The child's physical body development was assessed through anthropometric measurements. The weight was determined by weighing a child in kilograms using a digital weighing scale (Avery, United Kingdom) after removal of shoes and any overcoat. The values were corrected to the nearest one decimal point. The height of the child was measured when the child was standing while the back and knees were straight, and feet drawn together. The line of vision was in the horizontal plane. Then the height was measured from the heel to the uppermost part of the head using a wall mounted tape measure (Avery, United Kingdom) in metres and corrected to the nearest one decimal point.

\section{Reliability test}

There was no attempt to evaluate the error of the method of recording tooth eruption because the criteria for tooth emergence are so clear [17]. Blind duplicate measurement of the weight and height of about $10 \%(\mathrm{n}=$ 102) children was done to assess reproducibility of the 4 examiners at an interval of 7 days. This was based on systematic random selection of every $10^{\text {th }}$ child from the study sample. The intra-class correlation coefficients were calculated to check for consistency [18] in the anthropometric measurement of 102 children. The agreement was almost perfect with correlation coefficients between 0.85 and 0.96 for the weight and height of the children with no evidence of systematic error observed ( $>0.05$; paired $t$ test).

\section{Data analysis}

The data were analyzed using the Statistical Package for Social Science Inc. (SPSS, version 17 for windows, Chicago, Illinois, USA). The intra-class correlation analysis was used to check for consistency in the anthropometric measurement of the children. Student's $t$ test for paired observations was used to check for systematic errors in anthropometric measurements. The values of extracted teeth were converted to category 1, i.e. tooth having erupted. The eruption times were computed based on the technique previously described $[15,19]$. The mean and standard deviation of tooth eruption times were estimated for boys and girls. The standard error of the mean was calculated using the delta method [20]. Bivariate analysis was used to assess any association between tooth eruption times and the quantitative variables. Pearson and partial correlation analyses were used to determine any association between the mean tooth eruption times and anthropometric measurements. Body mass index (BMI) of each child was determined as the ratio of weight (in $\mathrm{kg}$ ) to the square of height (in $\mathrm{m}$ ). The likelihood ratio tests were used to assess any significant differences in mean eruption times between contra-lateral teeth of right and left quadrants as well as antagonistic teeth in mandible and maxilla.

Student's $t$ test for independent samples was used to test whether the correlation coefficient was significantly different from zero and to test differences between means of quantitative variables. The level of significance was set at $5 \%$.

\section{Results}

A total of 1041 children aged 4-15 years were consecutively recruited for the study. The overall mean age of the children was $8.8 \pm 3.0$ years (boys, $9.0 \pm 3.1$; girls, $8.6 \pm 3.0$, Table 1). The distribution of boys and girls based on chronological age was not significantly different $(\mathrm{p}>0.05)$.

Generally, the mean eruption times for girls were lower compared to boys except for three teeth (\#25, \#32 and \#42) which were found to erupt earlier in boys (Table 2). The average difference in mean eruption times of all teeth between boys and girls was 0.8 (range, $0-1.5$ )

Table 1 The frequency distribution of age and sex of the study children $(n=1041)$

\begin{tabular}{llll}
\hline Age (years) & Boys & Girls & All \\
\hline 4 & 42 & 44 & 86 \\
5 & 55 & 53 & 108 \\
6 & 52 & 72 & 124 \\
7 & 34 & 44 & 78 \\
8 & 32 & 44 & 76 \\
9 & 49 & 46 & 95 \\
10 & 53 & 52 & 105 \\
11 & 71 & 46 & 117 \\
12 & 57 & 67 & 124 \\
13 & 47 & 38 & 85 \\
14 & 22 & 10 & 32 \\
15 & 6 & 5 & 11 \\
All & 520 & 521 & 1041 \\
\hline
\end{tabular}


Table 2 The frequency distribution of number of cases, mean, standard deviation (SD) and standard error of the mean (SEM) of tooth eruption age (years) of boys and girls according to tooth types

\begin{tabular}{|c|c|c|c|c|c|c|c|c|c|c|c|c|}
\hline \multirow{2}{*}{$\begin{array}{l}\text { Tooth } \\
\text { number }\end{array}$} & \multicolumn{4}{|c|}{ Boys $(n=520)$} & \multicolumn{4}{|l|}{ Girls $(n=521)$} & \multicolumn{4}{|c|}{ All $(n=1041)$} \\
\hline & $\begin{array}{l}\text { No. of } \\
\text { cases }\end{array}$ & Mean & SD & $\overline{\text { SEM }}$ & No. of cases & Mean & SD & SEM & $\begin{array}{l}\text { No. of } \\
\text { cases }\end{array}$ & Mean & SD & $\overline{\text { SEM }}$ \\
\hline 11 & 69 & 6.3 & 0.8 & 0.3 & 48 & 6.1 & 2.1 & 0.9 & 117 & 6.2 & 1.5 & 0.5 \\
\hline 12 & 63 & 8.5 & 2.1 & 0.5 & 57 & 7.1 & 0.9 & 0.3 & 120 & 7.4 & 1.2 & 0.4 \\
\hline 13 & 143 & 10.9 & 1.2 & 0.2 & 72 & 9.4 & 1.2 & 0.3 & 215 & 10.4 & 1.4 & 0.2 \\
\hline 14 & 57 & 9.6 & 1.1 & 0.3 & 46 & 9.1 & 1.4 & 0.5 & 103 & 9.4 & 1.2 & 0.3 \\
\hline 15 & 42 & 10.0 & 1.0 & 0.4 & 26 & 9.6 & 1.3 & 0.5 & 68 & 9.8 & 1.2 & 0.4 \\
\hline 16 & 30 & 6.0 & 1.4 & 0.4 & 25 & 5.0 & 0.2 & 0.1 & 55 & 5.4 & 0.9 & 0.4 \\
\hline 17 & 49 & 10.8 & 1.0 & 0.5 & 32 & 10.5 & 1.3 & 0.5 & 81 & 10.6 & 1.2 & 0.3 \\
\hline 21 & 67 & 6.3 & 1.5 & 0.3 & 49 & 6.2 & 0.4 & 0.2 & 116 & 6.2 & 0.8 & 0.3 \\
\hline 22 & 65 & 8.4 & 1.4 & 0.5 & 51 & 7.2 & 1.0 & 0.3 & 116 & 7.8 & 1.3 & 0.3 \\
\hline 23 & 139 & 10.6 & 1.2 & 0.2 & 66 & 9.1 & 1.0 & 0.2 & 205 & 10.0 & 1.3 & 0.2 \\
\hline 24 & 59 & 9.5 & 1.3 & 0.4 & 50 & 9.4 & 1.3 & 0.4 & 109 & 9.4 & 1.3 & 0.3 \\
\hline 25 & 49 & 9.3 & 1.8 & 0.3 & 33 & 10.5 & 1.0 & 0.5 & 82 & 9.8 & 1.5 & 0.5 \\
\hline 26 & 30 & 6.7 & 2.0 & 0.4 & 26 & 5.5 & 1.0 & 0.5 & 56 & 6.3 & 1.8 & 0.5 \\
\hline 27 & 50 & 11.2 & 3.2 & 0.6 & 32 & 11.0 & 1.2 & 0.4 & 82 & 11.1 & 2.0 & 0.5 \\
\hline 31 & 44 & 6.0 & 0.9 & 0.2 & 21 & 5.5 & 2.7 & 0.9 & 61 & 5.7 & 2.1 & 0.5 \\
\hline 32 & 62 & 5.7 & 0.5 & 0.2 & 43 & 6.6 & 0.8 & 0.3 & 105 & 6.1 & 6.1 & 0.2 \\
\hline 33 & 72 & 10.0 & 1.7 & 0.4 & 58 & 10.0 & 2.5 & 0.9 & 130 & 10.0 & 2.0 & 0.4 \\
\hline 34 & 55 & 10.0 & 1.7 & 0.5 & 45 & 9.1 & 1.0 & 0.3 & 100 & 9.4 & 1.3 & 0.3 \\
\hline 35 & 35 & 10.5 & 1.0 & 0.1 & 23 & 10.3 & 1.1 & 0.4 & 58 & 10.4 & 1.1 & 0.3 \\
\hline 36 & 44 & 5.8 & 1.2 & 0.3 & 34 & 5.3 & 0.5 & 0.2 & 78 & 5.5 & 0.8 & 0.3 \\
\hline 37 & 85 & 11.5 & 1.7 & 0.4 & 63 & 6.1 & 2.1 & 0.9 & 148 & 6.2 & 1.5 & 0.5 \\
\hline 41 & 43 & 7.0 & 0.2 & 0.1 & 34 & 7.1 & 0.9 & 0.3 & 77 & 7.4 & 1.2 & 0.4 \\
\hline 42 & 67 & 5.8 & 0.5 & 0.3 & 43 & 9.4 & 1.2 & 0.3 & 110 & 10.4 & 1.4 & 0.2 \\
\hline 43 & 73 & 10.2 & 1.2 & 0.3 & 55 & 9.1 & 1.4 & 0.5 & 128 & 9.4 & 1.2 & 0.3 \\
\hline 44 & 55 & 9.9 & 1.7 & 0.5 & 47 & 9.6 & 1.3 & 0.5 & 102 & 9.8 & 1.2 & 0.4 \\
\hline 45 & 29 & 11.0 & 1.2 & 0.5 & 28 & 5.0 & 0.2 & 0.1 & 57 & 5.4 & 0.9 & 0.4 \\
\hline 46 & 46 & 6.2 & 1.3 & 0.2 & 39 & 10.5 & 1.3 & 0.5 & 85 & 10.6 & 1.2 & 0.3 \\
\hline 47 & 89 & 11.4 & 1.1 & 0.4 & 65 & 6.2 & 0.4 & 0.2 & 157 & 6.2 & 0.8 & 0.3 \\
\hline
\end{tabular}

years. The standard error of the mean ranged from 0.1 to 0.9 years for boys and 0.1 to 0.6 for girls (Table 2).

About $4 \%(n=21)$ of the boys and $4.4 \%(n=23)$ of the girls had missing teeth due to caries. Eight of the contralateral teeth on the left side had erupted slightly earlier that their right side counterparts (Table 2). The majority of the mandibular teeth tended to erupt earlier than the maxillary teeth with exception of second premolars and second molars (Table 2). The differences were not statistically significant $(\mathrm{p}>0.05)$.

Partial correlation coefficients of tooth eruption times with height while controlling for weight were positively, but not significantly associated $(\mathrm{p}>0.05)$ except for the mandibular left central incisor (\# 31, p $<0.05$; Table 3). On the other hand, partial correlation coefficients of tooth eruption times with weight while controlling for height were positively associated except for tooth \#11, \#16, \#26 and \#4.1 (Table 4). The weight of the child was significantly correlated with mean eruption times in 50\% of the teeth (Table 4). When Pearson linear correlation analysis was done between tooth eruption times and BMI, there was neither a specific pattern of coefficient values nor any significant correlation between the variables.

Generally, the mean eruption times of girls (Table 5) and boys (Table 6) in the present study were comparable with values from African countries (Ghana [21] and Nigeria [6]), but lower than values from countries outside Africa: Belgium [22], USA [23], Australia [24], Iran [25] and Pakistan [10]. 
Table 3 The partial correlation coefficients of tooth eruption ages of individual teeth with height while controlling for weight $(n=1041)$

\begin{tabular}{|c|c|c|c|}
\hline Tooth type & Number of cases & Correlation coefficient & $\mathrm{p}$-value \\
\hline 11 & 117 & 0.057 & 0.068 \\
\hline 12 & 120 & 0.058 & 0.061 \\
\hline 13 & 215 & 0.040 & 0.197 \\
\hline 14 & 103 & 0.052 & 0.097 \\
\hline 15 & 68 & 0.045 & 0.148 \\
\hline 16 & 55 & 0.043 & 0.163 \\
\hline 17 & 81 & 0.027 & 0.386 \\
\hline 21 & 116 & 0.055 & 0.076 \\
\hline 22 & 116 & 0.059 & 0.059 \\
\hline 23 & 205 & 0.037 & 0.239 \\
\hline 24 & 109 & 0.048 & 0.118 \\
\hline 25 & 82 & 0.046 & 0.141 \\
\hline 26 & 56 & 0.045 & 0.144 \\
\hline 27 & 82 & 0.023 & 0.451 \\
\hline $31^{*}$ & 61 & 0.113 & 0.001 \\
\hline 32 & 105 & 0.056 & 0.070 \\
\hline 33 & 130 & 0.047 & 0131 \\
\hline 34 & 100 & 0.048 & 0.120 \\
\hline 35 & 58 & 0.040 & 0.195 \\
\hline 36 & 78 & 0.044 & 0.152 \\
\hline 37 & 148 & 0.032 & 0.305 \\
\hline 41 & 77 & 0.048 & 0.122 \\
\hline 42 & 110 & 0.055 & 0.076 \\
\hline 43 & 128 & 0.048 & 0.124 \\
\hline 44 & 102 & 0.044 & 0.153 \\
\hline 45 & 57 & 0.041 & 0.183 \\
\hline 46 & 85 & 0.046 & 0.138 \\
\hline 47 & 157 & 0.031 & 0.313 \\
\hline
\end{tabular}

The mean eruption times of girls and boys in the present study were generally higher than previously recorded in Ugandan children [13]. The biggest difference in eruption times between the present study and the previous one [13) in girls was 1.7 years in the mandibular canine (Table 5) while among the boys was 1.3 years in the mandibular second molar (Table 6). In the previous national survey [13] of the Ugandan children, tooth eruption times were generally earlier in girls with a difference of an average of 0.5 (range, $0-1.6$ ) years. On the other hand, tooth \#11, \#16, \#26 and \#46 erupted earlier in boys.

\section{Discussion}

In this cross sectional study, the eruption times of the permanent teeth and the anthropometric measurements
Table 4 The partial correlation coefficients of tooth eruption ages of individual teeth with weight while controlling for height $(n=1041)$

\begin{tabular}{|c|c|c|c|}
\hline Tooth type & Number of cases & Correlation coefficient & $p$-value \\
\hline 11 & 117 & -0.017 & 0.584 \\
\hline 12 & 120 & 0.044 & 0.154 \\
\hline 13 & 215 & 0.241 & $<0.001$ \\
\hline 14 & 103 & 0.154 & $<0.001$ \\
\hline 15 & 68 & 0.163 & $<0.001$ \\
\hline 16 & 55 & -0.016 & 0.604 \\
\hline 17 & 81 & 0.264 & $<0.001$ \\
\hline 21 & 116 & 0.010 & 0.742 \\
\hline 22 & 116 & 0.040 & 0.197 \\
\hline 23 & 205 & 0.257 & $<0.001$ \\
\hline 24 & 109 & 0.158 & $<0.001$ \\
\hline 25 & 82 & 0.162 & $<0.001$ \\
\hline 26 & 56 & -0.010 & 0.748 \\
\hline 27 & 82 & 0.288 & $<0.001$ \\
\hline 31 & 61 & 0.030 & 0.331 \\
\hline 32 & 105 & 0.008 & 0.798 \\
\hline 33 & 130 & 0.209 & $<0.001$ \\
\hline 34 & 100 & 0.220 & $<0.001$ \\
\hline 35 & 58 & 0.209 & $<0.001$ \\
\hline 36 & 78 & 0.016 & 0.614 \\
\hline 37 & 148 & 0.279 & $<0.001$ \\
\hline 41 & 77 & -0.030 & 0.338 \\
\hline 42 & 110 & 0.014 & 0.658 \\
\hline 43 & 128 & 0.202 & $<0.001$ \\
\hline 44 & 102 & 0.224 & $<0.001$ \\
\hline 45 & 57 & 0.208 & $<0.001$ \\
\hline 46 & 85 & 0.208 & 0.189 \\
\hline 47 & 157 & 0.284 & 0.001 \\
\hline
\end{tabular}

were evaluated in a group of Ugandan school children aged between 4 to 15 years in Kampala. The data comprised of 1041 children with an almost equal distribution according to sex (520:521/boys: girls; Table 1). In some cultural practices indigenous to each region, data related to the date of birth might be misleading, especially if no central registration boards or no precise proof of age exist [26]. In the present study, the age of the child was ascertained by asking the child the date of birth and then confirmed with school records. The two sources of information corroborated.

The eruption or emergence of a tooth is the biological process that follows the formation of the dental crown and is essentially the penetration of the covering oral mucosa by any part of a tooth [1]. In the present study, clinical assessment of penetration of the oral mucosa by 
Table 5 Comparison of mean eruption ages (years) of Ugandan girls with those of other nationalities in the respective year of study

\begin{tabular}{|c|c|c|c|c|c|c|c|c|c|}
\hline Tooth type & $\begin{array}{l}\text { Belgium } \\
(2003)\end{array}$ & $\begin{array}{l}\text { Ghana } \\
(1967)\end{array}$ & $\begin{array}{l}\text { Nigeria } \\
(1971)\end{array}$ & $\begin{array}{l}\text { USA } \\
\text { (1978) }\end{array}$ & $\begin{array}{l}\text { Australia } \\
(2003)\end{array}$ & $\begin{array}{l}\text { Iran } \\
(2004) \\
\end{array}$ & $\begin{array}{l}\text { Pakistan } \\
(2011)\end{array}$ & $\begin{array}{l}\text { Uganda } \\
\text { (1971) }\end{array}$ & $\begin{array}{l}\text { Uganda } \\
\text { (Present) }\end{array}$ \\
\hline \multicolumn{10}{|l|}{ Maxillary } \\
\hline Central incisor & 6.9 & 6.0 & 7.1 & 7.2 & 7.2 & 7.6 & 7.5 & 6.2 & 6.2 \\
\hline Lateral incisor & 7.9 & 7.3 & 8.0 & 8.2 & 8.2 & 8.8 & 8.4 & 6.9 & 7.2 \\
\hline Canine & 110 & 9.5 & 10.2 & 11.0 & 11.2 & 12.1 & 107 & 9.3 & 9.3 \\
\hline First premolar & 10.4 & 9.0 & 10.1 & 10.5 & 10.8 & 11.0 & 10.1 & 8.8 & 9.3 \\
\hline Second premolar & 11.4 & 10.0 & 10.3 & 12.2 & 11.7 & 12.5 & 10.8 & 9.6 & 10.1 \\
\hline First molar & 6.2 & 5.0 & 5.8 & 6.4 & 6.5 & 6.7 & 6.7 & 5.4 & 5.3 \\
\hline Second molar & 12.0 & 10.9 & 11.4 & 12.1 & 12.3 & 12.5 & 12.0 & 9.8 & 10.7 \\
\hline \multicolumn{10}{|l|}{ Mandibular } \\
\hline Central incisor & 6.2 & 5.1 & 5.8 & 6.1 & 6.3 & 6.5 & 7.1 & 5.3 & 5.6 \\
\hline Lateral incisor & 7.1 & 6.3 & 7.3 & 7.3 & 7.4 & 7.9 & 7.9 & 6.0 & 6.8 \\
\hline Canine & 9.7 & 8.9 & 9.9 & 9.9 & 10.1 & 10.3 & 10.0 & 8.0 & 9.7 \\
\hline First premolar & 10.3 & 9.2 & 9.9 & 10.4 & 10.6 & 11.1 & 10.3 & 8.9 & 9.2 \\
\hline Second premolar & 11.4 & 10.3 & 10.6 & 11.1 & 11.7 & 12.6 & 10.8 & 9.8 & 10.2 \\
\hline First molar & 6.2 & 4.4 & 5.8 & 6.3 & 6.3 & 6.7 & 6.5 & 5.4 & 5.2 \\
\hline Second molar & 11.6 & 10.5 & 10.9 & 11.8 & 11.8 & 12.4 & 11.4 & 9.4 & 10.3 \\
\hline
\end{tabular}

any part of the tooth was so obvious and did not require any reliability assessment of the examiners [17]. However, the reliability test of anthropometric measurement was done and gave an almost perfect agreement [18] with no evidence of systematic error observed.
The present study was school based with no radiological facilities available and consequently, we were not able to determine the level of congenitally missing teeth. Previously, Holman and Jones [27] had discussed the impact of congenitally missing teeth on the mean eruption

Table 6 Comparison of mean eruption ages (years) of Ugandan boys with those of other nationalities in the respective year of study

\begin{tabular}{|c|c|c|c|c|c|c|c|c|c|}
\hline Tooth type & $\begin{array}{l}\text { Belgium } \\
(2003)\end{array}$ & $\begin{array}{l}\text { Ghana } \\
(1967)\end{array}$ & $\begin{array}{l}\text { Nigeria } \\
(1971)\end{array}$ & $\begin{array}{l}\text { USA } \\
(1978)\end{array}$ & $\begin{array}{l}\text { Australia } \\
(2003)\end{array}$ & $\begin{array}{l}\text { Iran } \\
(2004)\end{array}$ & $\begin{array}{l}\text { Pakistan } \\
(2011)\end{array}$ & $\begin{array}{l}\text { Uganda } \\
\text { (1971) }\end{array}$ & $\begin{array}{l}\text { Uganda } \\
\text { (Present) }\end{array}$ \\
\hline \multicolumn{10}{|l|}{ Maxillary } \\
\hline Central incisor & 7.1 & 6.2 & 7.5 & 7.2 & 7.4 & 6.8 & 7.5 & 6.1 & 6.3 \\
\hline Lateral incisor & 8.3 & 7.4 & 8.3 & 8.3 & 8.6 & 8.4 & 8.5 & 7.3 & 8.5 \\
\hline Canine & 11.5 & 10.0 & 11.0 & 11.5 & 11.8 & 11.8 & 11.0 & 10.0 & 10.8 \\
\hline First premolar & 10.7 & 9.3 & 10.6 & 11.1 & 11.3 & 12.0 & 10.1 & 9.0 & 9.6 \\
\hline Second premolar & 11.6 & 10.3 & 11.1 & 11.7 & 12.1 & 12.0 & 10.1 & 10.5 & 9.5 \\
\hline First molar & 6.3 & 5.0 & 6.3 & 6.5 & 6.7 & 6.8 & 6.7 & 5.1 & 6.4 \\
\hline Second molar & 12.3 & 10.9 & 11.8 & 12.2 & 12.7 & 12.7 & 11.7 & 10.5 & 10.0 \\
\hline \multicolumn{10}{|l|}{ Mandibular } \\
\hline Central incisor & 6.3 & 5.2 & 6.3 & 6.2 & 6.6 & 6.0 & 6.7 & 5.5 & 6.5 \\
\hline Lateral incisor & 7.4 & 6.3 & 7.3 & 7.5 & 7.8 & 7.3 & 8.4 & 6.2 & 5.8 \\
\hline Canine & 10.6 & 9.5 & 10.6 & 10.7 & 11.0 & 9.7 & 11.8 & 9.6 & 10.1 \\
\hline First premolar & 10.7 & 9.5 & 10.7 & 10.9 & 11.2 & 10.1 & 12.2 & 9.6 & 10.0 \\
\hline Second premolar & 11.7 & 10.5 & 10.5 & 11.6 & 12.1 & 10.9 & 12.8 & 10.4 & 10.8 \\
\hline First molar & 6.3 & 4.7 & 6.0 & 6.5 & 6.6 & 5.6 & 6.8 & 5.3 & 6.0 \\
\hline Second molar & 11.8 & 10.6 & 11.3 & 12.0 & 12.2 & 11.3 & 12.9 & 10.2 & 11.5 \\
\hline
\end{tabular}


times and concluded that estimates of eruption time without considering congenitally missing teeth were biased upward, but in any case less than 1\%. Moreover, they stated that for adequate sample sizes, agenesis does not lead to substantially biased estimates. The present study recruited a moderate sample size of children ( $\mathrm{n}=$ 1041) implying that the influence of congenitally missing teeth may not be significant.

Researchers in previous studies $[1,4,28]$ postulated that there was a role of the endogenic, exogenic and/or environmental factors in tooth eruption time. Socioeconomic or environmental factors have been reported to directly influence nutrition with an impact on child development including tooth eruption $[7,8]$, although Friedlaeder and Bailit [29] expressed a relative unimportance of environmental influence on eruption times of permanent teeth. Tooth eruption times in Uganda was last studied more than 40 years ago [13]. Over that period many environmental and socioeconomic changes have taken place, which included civil wars leading to internal migration and disruption of socioeconomic activities. However, with peaceful environment in the subsequent years, this was followed by an impressive economic growth [30] that improved the socioeconomic development and presumably, the nutritional status of individuals. It could be argued that these changes may partly explain the later eruption times in the present compared to the previous study [13] (Tables 5 and 6). Assessment of the role of the endogenous, exogenous or socioeconomic and environmental factors in tooth eruption was beyond the scope of the present study. Other factors that could lead to observed differences in the eruption times between the two studies are that the previous study [13] was a national estimate based on a smaller sample of children ( $\mathrm{n}=622)$.

Based on partial correlation analyses in the present study, the mean tooth eruption times were directly related to child height, although the relationship was generally not statistically significant (Table 3). On the other hand, eruption times were generally directly related to the weight of the child, but significant in $50 \%$ of the teeth (Table 4) indicating that the influence of weight on eruption time is non-conclusive. In a previous comparative study [31] among the Japanese children in Hiroshima, tooth eruption times were found to be directly influenced by height and weight.

In further analysis based on Pearson linear correlation, we did not observe any specific relationship between tooth eruption times and BMI probably due to conflicting outcomes of weight and height. Among the Pakistani children in Karachi, Khan [10] previously observed that tall children exhibited delayed tooth eruption irrespective of their weight while heavy and short children had early tooth eruption. He also found the eruption time of different teeth to be either directly or indirectly related to the BMI. In other studies involving first molars and incisors of Saudi male children in Riyadh and Jeddah, Khan et al. [3] observed a non significant correlation between BMI and eruption times except for tooth \#32. The eruption times were generally inversely related to the BMI.

In the present study, we found a sex difference in tooth eruption times; being an average of 0.8 (range, 01.5) years earlier in girls (Table 2). Similarly, in the previous survey in Uganda [13], eruption times were lower in girls than boys with a difference of an average of 0.5 (range, 0-1.6) years. Additionally, we found tooth \#25, $\# 32$ and \#42 to have erupted earlier in boys than girls while in the previous study [13] tooth \#11, \#16, \#26 and \#46 erupted earlier in boys than girls. The reason for the differences in tooth eruption times between boys and girls is poorly understood. It is assumed that the earlier onset of the permanent dentition is part of the different sexual maturity of both sexes at a given age [32].

In the present study, about $4 \%$ and $4.4 \%$ of the boys and girls, respectively, had lost teeth due to caries. By assumption, the prevalence of extracted teeth due to caries in the deciduous dentition could have been at the same low level in these Ugandan children. Retained deciduous teeth till physiological shedding could retard the eruption of permanent teeth [13].

We found no significant differences in the mean eruption times between the teeth in the right and left side of the jaws in these Ugandan children, which corroborates findings in the previous reports [10,33].

Generally, there were no substantial differences between the mean eruption times of the children in the present study and other studies involving African populations (Tables 5 and 6). However, our results showed lower values when compared with studies from outside Africa. The major differences in eruption times among girls in both the maxillary and mandibular teeth were with the Iranian children [25] (Table 5) while among the boys, bigger differences were with the Australian [24] and Iranian children [25] in the maxillary teeth and Pakistani children [10] in the mandibular teeth (Table 6). The impact of ethnicity on the eruption process was reported in previous surveys [2,4-6] and meta-analysis [34].

\section{Conclusion}

The mean tooth eruption times for girls were lower compared to boys except for three teeth (\#25, \#32 and $\# 42$ ). The height of the child did not show any significant influence on the tooth eruption times while the influence of weight on tooth eruption times was nonconclusive.

Competing interests

The authors declare that they have no competing interests. 


\section{Authors' contributions}

AK wrote the protocol, contributed to data collection and drafted the manuscript. CMR analysed the data and contributed to the manuscript writing. ER, LM and WB developed the study idea and contributed to the study design, data collection, literature review and writing of the manuscript. All the authors read and approved the final manuscript.

\section{Acknowledgements}

We are grateful to the children who participated in the study. The school teachers were instrumental in mobilising the children. The study was funded by SIDA/ Sarec through Makerere University, College of Health Sciences.

\section{Author details}

'Department of Dentistry College of Health sciences, Makerere University, P.O. Box 7072, Kampala, Uganda. '2Department of Anatomy, College of Health sciences, Makerere University, Kampala, Uganda.

Received: 9 November 2012 Accepted: 7 March 2013

Published: 16 March 2013

\section{References}

1. Bailit HL, Sung B: Maternal effects on the dentition. Arch Oral Bio/ 1968, 13:155-162.

2. Agarwal KN, Gupta R, Faridi MMA, Kalra N: Permanent dentition in Delhi boys of age 5-14. Indian Pediatr 2004, 41:1031-1035

3. Khan NB, Chohan AN, AlMograbi B, AlDeyab S, Zahid T, AlMoutairi M: Eruption time of permanent first molars and incisors among a sample of Saudi male schoolchildren. Saudi Dent J 2006, 18:18-24.

4. Billewicz WZ, McGregor IA: Eruption of permanent teeth in West African (Gambian) children in relation to age, sex and physique. Ann Hum Biol 1975, 2:17-28.

5. Pahkala R, Pahkala A, Laine T: Eruption pattern of permanent teeth in a rural community in North Eastern Finland. Acta Odontol Scand 1991, 49:341-349.

6. Akpata ES: Eruption times of permanent teeth in southern Nigerians. J Nigerian Med Assoc 1971, 1:34-35.

7. Adler P: Effect of some environmental factors on sequence of permanent tooth eruption. J Dent Res 1963, 42:605-616.

8. Lee MMC, Low WD, Chang SFS: Eruption of the permanent dentition of Southern Chinese children in Hong Kong. Arch Oral Biol 1965, 10:849-861.

9. Triratana T, Hemindra, Kiatiparjuk C: Eruption of permanent teeth in malnourished children. J Dent Assoc Thai 1990, 40:100-108.

10. Khan N: Eruption time of permanent teeth in Pakistani children. Iranian J Publ Health 2011, 40:63-73.

11. Kaur B, Singh R: Physical growth and age at eruption of deciduous and permanent teeth in well nourished Indian girls from birth to twenty years. Am J Hum Biol 1992, 4:757-766.

12. Fillipson $\mathrm{R}$, Hall $\mathrm{K}$ : Correlation between dental maturity, height development and sexual maturation in normal girls. Ann Hum Biol 1976, 3:205-210.

13. Krumholt L, Roed-Petersen B, Pindborg JJ: Eruption times of the permanent teeth in 622 Ugandan children. Arch Oral Biol 1971, 16:1281-1288

14. World Medical Association: Declaration of Helsinki, version VI. 2002. [http:// www.wma.net/en/30publications/10policies/b3/17c.pdf]. Accessed on 8 November 2012.

15. Gates RE: Computation of the mean age of eruption of permanent teeth using probit analysis and an electronic computer. J Dent Res 1966, 45:1024-1028

16. World Health Organization: Oral health surveys. Basic method. 4th edition Geneva: World Health Organization; 1997.

17. Virtanen J, Bloigu RS, Larmas MA: Timing of eruption of permanent teeth: standard Finnish patient documents. Community Dent Oral Epidemiol 1994 22:286-288.

18. Portney LG, Watkins MP: Foundations of clinical research Applications to practice. New Jersey: Prentice Hall Inc; 2000:560-567.

19. Hayes RL, Mantel N: Procedures for computing the mean age of eruption of deciduous teeth. J Dent Res 1958, 38:938-947.

20. Cox DR, Hinkley CV: Theoretical statistics. London: Chapman and Hall; 1974.

21. Houpt Ml, Adu-Aryee S, Grainger RM: Eruption times of permanent teeth in the Brong Ahafo region of Ghana. Am J Orthodont 1967, 53:95-99.
22. Leroy R, Bogaerts K, Lesaffre E, Declerck D: The emergence of permanent teeth in Flemish children. Comm Dent Oral Epidemiol 2003, 2003(31):30-39.

23. Savara BS, Steen JC: Timing and sequence of eruption of permanent teeth in longitudinal sample of children from Oregon. J Am Dent Assoc 1978, 97:209-214.

24. Diamanti J, Townsend GC: New standards for permanent tooth emergence in Australian children. Aust Dent J 2003, 2003(48):39-42.

25. Moslemi M: An epidemiological survey of the time and sequence of eruption of permanent teeth in 4-15-year-olds in Tehran, Iran. Int J Paediatr Dent 2004, 14:432-438.

26. Mutebi FH: Use of secondary data in health research. MPH thesis: Uganda Christian University, Uganda, Public Health Department; 2010.

27. Holman DJ, Jones RE: Longitudinal analysis of deciduous tooth emergence, Part II. Parametric survival analysis in Bangladeshi, Guatemalan, Japanese, and Javanese children. Am J Phys Anthropol 1998, 105:209-230.

28. Campagna L, Tsamtsouris A, Kavadia K: Fluoridated drinking water and maturation of permanent teeth at age 12. J Clin Pediatr Dent 1995, 19:225-228.

29. Friedlaender JS, Bailit HL: Eruption times of the deciduous and permanent teeth of natives on Bougainville Island, Territory of New Guinea: a study of racial variation. Hum Biol 1969, 41:51-65.

30. Uganda Bureau of Statistics: Uganda population and housing census analytical report: Gender and special interest groups. 2002. [http://www.ubos. org/onlinefiles/uploads/ubos/pdf\%20documents/2002\% 20CensusPopnSizeGrowthAnalyticalReport.pdf]. Accessed on 23.12. 2012

31. Niswander JD, Sujaku C: Dental eruption, stature and weight of Hiroshima children. J Dent Res 1960, 39:959-963.

32. Ritz-Timme S, Cattaneo C, Collins MJ, Waite ER, Schütz HW, Kaatsch HJ, Borrman HIM: Age estimation: the state of the art in relation to the specific demands of forensic practice. Int J Legal Med 2000, 113:129-136.

33. Clement EMB, Davies-Thomas E, Pickett CG: Time of eruption of permanent teeth in British children 1947-8. Br Med J 1953, 1:1421-1424.

34. Wedl JS, Stiefel BG, Friedrich RE, Dietz K, Schmelzle R: Clinical oral investigation of permanent teeth eruption as an aid for forensicodontological estimations of the chronological age in children and adolescents. Rechtsmedizin 2002, 2:87-99.

doi:10.1186/1472-6831-13-15

Cite this article as: Kutesa et al:: Weight, height and eruption times of permanent teeth of children aged 4-15 years in Kampala, Uganda. BMC Oral Health 2013 13:15.

\section{Submit your next manuscript to BioMed Central and take full advantage of:}

- Convenient online submission

- Thorough peer review

- No space constraints or color figure charges

- Immediate publication on acceptance

- Inclusion in PubMed, CAS, Scopus and Google Scholar

- Research which is freely available for redistribution 